\title{
Prevalence of soil transmitted nematodes on Nukufetau, a remote Pacific island in Tuvalu
}

\author{
Rick Speare*1, Falatea Fab Latasi ${ }^{2}$, Tekaai Nelesone ${ }^{2}$, Sonia Harmen ${ }^{1}$, \\ Wayne Melrose ${ }^{1}$, David Durrheim ${ }^{1,3}$ and Jorg Heukelbach ${ }^{4}$
}

\begin{abstract}
Address: ${ }^{1}$ Anton Breinl Centre for Public Health and Tropical Medicine, WHO Collaborating Centre for Lymphatic Filariasis, James Cook University, Townsville 4811, Queensland, Australia, ${ }^{2}$ Ministry of Health, Funafuti, Tuvalu, ${ }^{3}$ Health Protection, Hunter New England Population Health, Locked Bag 10, Wallsend 2287, New South Wales, Australia and ${ }^{4}$ Department of Community Health, School of Medicine, Federal University of Ceará, Fortaleza CE 60430-140, Brazil

Email: Rick Speare* - richard.speare@jcu.edu.au; Falatea Fab Latasi - richard.speare@jcu.edu.au; Tekaai Nelesone - ttafune@yahoo.com.au; Sonia Harmen - sonia.harmen@jcu.edu.au; Wayne Melrose - wayne.melrose@jcu.edu.au;

David Durrheim - david.durrheim@hnehealth.nsw.gov.au; Jorg Heukelbach - heukelbach@web.de

* Corresponding author
\end{abstract}

Published: 12 July 2006

BMC Infectious Diseases 2006, 6:110 doi:10.1186/147/-2334-6-110

Received: 06 January 2006

Accepted: 12 July 2006

This article is available from: http://www.biomedcentral.com/I47I-2334/6/II0

(C) 2006 Speare et al; licensee BioMed Central Ltd.

This is an Open Access article distributed under the terms of the Creative Commons Attribution License (http://creativecommons.org/licenses/by/2.0), which permits unrestricted use, distribution, and reproduction in any medium, provided the original work is properly cited.

\begin{abstract}
Background: The population of Nukufetau, a remote coral atoll island in Tuvalu in the Western Pacific, received annual mass drug administration (MDA) of diethylcarbamazine and albendazole under the Pacific Elimination of Lymphatic Filariasis program in 200I, 2002 and 2003, with the last MDA occurring six months before a cross-sectional survey of the whole population for soil transmitted helminths (STH).
\end{abstract}

Methods: A cross-sectional survey in May 2004 recruited 206 residents (35.2\% of the population) who provided a single faecal sample that was preserved, concentrated and examined microscopically.

Results: Overall prevalence of STH was 69.9\%; only hookworm and Trichuris trichiura were diagnosed. Trichuris was present in $68.4 \%$ with intensity of infection being light in $56.3 \%$, medium in $11.7 \%$ and heavy in $0.5 \%$. Hookworm occurred in $11.7 \%$ with intensity of infection $11.2 \%$ being light and medium in $0.5 \%$. Twenty individuals $(9.7 \%)$ had dual infections. The prevalence of Trichuris was constant across all ages while the prevalence of hookworm was significantly lower in residents below 30 years of age. In the age group 5-12 years comparison of results with a 200I survey [I] suggested that the prevalence of STH has declined minimally, due to sustained high prevalence of Trichuris, while hookworm has declined dramatically from $34.4 \%$ to $1.6 \%$.

Conclusion: The results of this survey suggest that although the MDA appears to have reduced hookworm prevalence in residents below 30 years of age, there has been minimal effect on Trichuris prevalence. An integrated program to control STH is required.

\section{Background}

Infections with soil transmitted helminths (STH) are common worldwide, with prevalence and parasite burden being particularly high in developing countries among school-aged children [2], although in many communities the prevalence of hookworm is higher in adults than in 


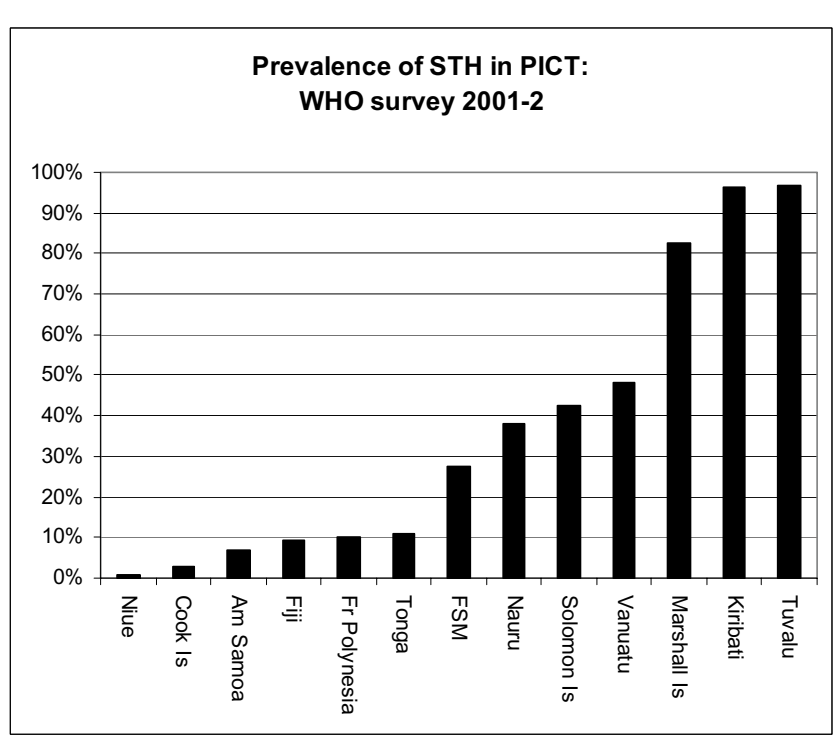

Figure I

Prevalences of soil transmitted nematodes in children aged 5-12 years in PICT in 200I-2 (data reanalysed from Hughes et al 2004 [I] table 4).

children [3]. In children, STH are associated with anaemia, stunting, underweight and poor school performance $[4,5]$.

A survey of STH in 13 Pacific island countries and territories (PICT) in 2001-2 found a very narrow spectrum of nematode parasites in children with a wide range of prevalences [1]. In this survey, prevalences in children aged 5 to 12 years ranged between $1 \%$ and $97 \%$ with prevalences lower then $5 \%$ in Niue and the Cook Islands, but very high prevalences $(>80 \%)$ on the Marshall Islands, Kiribati, and Tuvalu (Fig 1). The reasons for this variation are not known.

In Tuvalu, samples from 118 children were analyzed, with 32 of these from the island of Nukufetau. Tuvalu had the highest prevalence (97\%) of the 13 PICT, and only hookworms and whipworms (Trichuris trichiura) were detected [1]. There was not a single case of Ascaris infection. The species of hookworm was not identified. Two schools were surveyed, one on the main island of Funafuti with a resident population of 4,452, and another on the remote island of Nukufetau, with a resident population of 585 .

Tuvalu had no programs or strategies to control STH before 2001, but in 2001, after the faecal survey, annual mass drug administration (MDA) of diethylcarbamazine (DEC) and albendazole was commenced for lymphatic filariasis elimination [6]. MDA was administered to all residents aged two years and older except for pregnant women and people considered too ill due to other dis- eases. The coverage (number of residents who received and consumed the drugs/total population) for Tuvalu was $81 \%$ in $2001,47 \%$ in 2002 and $83 \%$ in 2003 [6].

This paper reports the results of a survey for STH amongst all age groups of Nukufetau residents in 2004, three years after the previous school-based survey [1] and following three rounds of MDA using albendazole and DEC. The survey was an opportunistic one, not linked to the MDA, but initiated to establish the need for a STH control program. The latest MDA had occurred six months prior to this survey.

\section{Methods}

A cross-sectional survey was conducted on the island of Nukufetau, Tuvalu. Nukufetau is located at $\mathrm{S}^{\circ} 15^{\prime}$ E178 $22^{\prime}$, approximately $110 \mathrm{~km}$ north west of Funafuti, the capital island of Tuvalu. At the time of the last census in 2002, the island had 585 residents. All islands in Tuvalu are coral atolls.

In May 2004, all residents of Nukufetau were provided with containers for collection of faeces. To each specimen returned, SAF (sodium acetate, acetic acid and formaldehyde) solution was added, approximately equal to the volume of the faecal sample, and the faeces macerated to form a slurry. The fixed samples were transported to Princess Margaret Hospital Laboratory (PMHL) on Funafuti for examination. Details recorded for each sample were the resident's name, age and gender.

At the PMHL approximately $0.2 \mathrm{~g}$ of faeces was placed in a plastic conical $10 \mathrm{ml}$ centrifuge tube with $8 \mathrm{ml}$ of $10 \%$ formalin and $1 \mathrm{ml}$ of petrol, and vigorously shaken by hand. The tubes were then centrifuged for $10 \mathrm{~min}$ at roughly $500 \mathrm{G}$. The ring of petrol and associated debris was loosened in each tube and all fluid in the tube tipped out. Volume was then reconstituted to $1 \mathrm{ml}$ using tap water, mixed and $0.05 \mathrm{ml}$ examined under two cover-slips $(24 \times 24 \mathrm{~mm})$ placed side by side on a microscope slide at $\times 100$ magnification using a compound light microscope. One slide was prepared from each specimen. Results were reported as number of eggs seen per slide and then calculated as eggs per gram (EPG) by multiplying by 200. The multiplication factor was determined by dilution of original sample at fixation $(\times 2), 0.2 \mathrm{~g}$ in test tube $(\times 5)$, examination of $0.05 \mathrm{ml}$ of $1 \mathrm{ml}(\times 20)$. Egg results were reported as light, medium and heavy using the criteria of WHO [7]: an egg count of 1-999, 1000-9999 and $\geq 9999$ EPG was considered as light, moderate and heavy infection for $T$. trichiura, and 1-1999, 2000-3999 and $\geq 3999$ EPG as light, moderate and heavy infection for hookworms.

Data was entered into an Excel file, checked for errors that may have occurred during data entry and analysed using 
Table I: Prevalence of STH in Nukutefau residents by age-group, 2004. Population data are from 2002 census.

\begin{tabular}{|c|c|c|c|c|c|c|}
\hline Age group (years) & Total population & $\begin{array}{c}\text { Number } \\
\text { examined (\% pop } \\
\text { of age group) }\end{array}$ & Hookworm positive (\%) & Trichuris positive (\%) & STH positive (\%) & $\begin{array}{c}\text { Trichuris } \\
\text { Geometric Mean } \\
\text { Intensity EPG* }\end{array}$ \\
\hline $0-9$ & 171 & $62(36.3)$ & I (I.6) & $43(69.4)$ & $43(69.4)$ & 54.2 \\
\hline $10-19$ & 95 & $26(27.4)$ & I (3.8) & $19(73.1)$ & $19(73.1)$ & 67.6 \\
\hline $20-29$ & 51 & $6(11.8)$ & $0(0.0)$ & $5(83.3)$ & $5(83.3)$ & 40.9 \\
\hline $30-39$ & 70 & $15(2 \mid .4)$ & $3(20.0)$ & $10(66.7)$ & $10(66.7)$ & 35.3 \\
\hline $40-49$ & 79 & $25(31.6)$ & $5(20.0)$ & $16(64.0)$ & $17(68.0)$ & 17.6 \\
\hline $50-59$ & 52 & 37 (7I.2) & $9(24.3)$ & $27(73.4)$ & $27(73.0)$ & 56.0 \\
\hline $60-69$ & 47 & 23 (48.9) & $3(13.0)$ & $13(56.5)$ & $14(60.9)$ & 20.3 \\
\hline$\geq 70$ & 20 & $12(60.0)$ & $2(16.7)$ & $8(66.7)$ & $9(75.0)$ & 35.5 \\
\hline Total & 585 & $206(35.2)$ & $24(11.7)$ & $|4|(68.4)$ & $144(69.9)$ & 41.2 \\
\hline $\mathrm{Cl} 0.95$ & & & $9.5-13.9 \%$ & $65.2-71.6 \%$ & $66.7-73.1 \%$ & \\
\hline
\end{tabular}

*Geometric Mean Intensity EPG calculated for all subjects as per Mani et al (2004).

SPSS for Windows (version 12.0.1) to generate descriptive statistics. Chi-square tests were used to test for differences in prevalence by gender and age category. Geometric mean intensity of EPG for Trichuris was calculated for all participants. The study was performed under James Cook University Ethics Committee Approval number H1423 and with the permission and full involvement of the Ministry of Health, Tuvalu.

\section{Results}

Two hundred and six specimens were collected, $35.2 \%$ of the population of Nukufetau. Males provided 96 specimens (46.6\%) and females 110 (53.4\%). Mean age was 33 years with a median of 34 years and a range from seven months to 84 years. All age-groups were represented (Table 1) with 20-29 years under-represented at $11.8 \%$ and $>49$ years over-represented at $60.5 \%$. STH were diagnosed in 69.9\%. (Table 1 ).

Only hookworm and Trichuris infections were diagnosed. The overall prevalence of hookworm was $11.7 \%$ with a prevalence of $2.1 \%$ in residents under 30 years of age and $19.6 \%$ amongst residents 30 years of age or older (Table $1)$. There was a significant difference in prevalence by age category $(\mathrm{p}=.014)$. The overall prevalence of Trichuris was $68.4 \%$ with no significant difference in prevalence by age group. Twenty $(9.7 \%)$ residents had concomitant infections with hookworm and Trichuris, and only three were infected by hookworm alone. There was no significant difference in prevalence of Trichuris or hookworm infections by gender.

Amongst the 61 children aged 5-12 years, 46 (75.4\%) had STH, all with Trichuris and one (1.6\%) had a concomitant infection with hookworm. Fifty percent $(12 / 24)$ of the children less than 5 years had STH including 25\% of the 12 children 2 years of age and younger. Only one child under 5 years, a 4 year old, had hookworm infection. This child also had Trichuris as did the remaining 12 STH pos- itive children. The youngest child with Trichuris was 1 year of age.

For individuals with Trichuris infection the mean $( \pm$ std) and maximum EPG were $673( \pm 1510)$ and 15,200 respectively. The proportions with light, medium and heavy infections were $56.3 \%, 11.7 \%$ and $0.5 \%$ respectively. For hookworm the mean $( \pm$ std) and maximum EPG were 242 $( \pm 407)$ and 2,040 respectively. The proportions with light and medium infections were $11.2 \%$ and $0.5 \%$ respectively. There were no heavy infections. For the 61 children 5-12 years of age surveyed, intensity of infection with Trichuris was light in $57.4 \%$, medium in $16.4 \%$ and heavy in $1.6 \%$.

\section{Discussion}

To the best of our knowledge, this is the first published cross-sectional prevalence survey of STH amongst an entire island population in the Western Pacific Region. The prevalence of STH in this remote atoll island was high (69.9\%), mainly due to infection with $T$. trichiura, and the spectrum of geohelminths was narrow. Trichuriasis was equally distributed across all ages while the prevalence of hookworm infection was low $(2.1 \%)$ under 30 years of age, but $19.6 \%$ in residents aged 30 years or older. Since the species of hookworm in Tuvalu is unknown, the high prevalence warrants studies to determine the species and to evaluate the health impact of hookworm infection, particularly the possible occurrence of iron deficiency anaemia in reproductive age and older women. Interestingly, not a single case of Ascaris infection was detected, confirming Hughes et al's findings for Tuvalu [1].

The only available baseline data on STH for the population of Nukufetau prior to the MDA campaigns comes from the survey amongst children aged 5-12 years in 2001 [1]. Although the prevalence of STH in this age range has changed only slightly in Nukufetau since 2001, this is due to the high prevalence of Trichuris. In the survey in 
2001 in the age group 5-12 years, prevalence of Trichuris was $84 \%(\mathrm{n}=32)$ while in our survey prevalence was $75 \%$ $(n=61)$, a decline in prevalence of $11 \%$. However, hookworm has declined dramatically in this age-group from $34.4 \%$ to $1.6 \%$, a $95 \%$ reduction in prevalence. Intensity of infection with hookworm has remained constant with all cases in the light category [1]. Intensity of Trichuris in this age group has not changed significantly, with light $59.4 \%$ and medium $25 \%$ in 2001 and light $57.4 \%$, medium $16.4 \%$ and heavy $1.6 \%$ in this survey. However, direct comparison is difficult since the participants in neither survey were randomly selected [8]. Only one of the 24 children under 5 years, a 4 year old, had hookworm, a prevalence of $4.2 \%$ for children less than 5 years of age. Children less than 3 years at the time of this survey had not participated in any MDA round, while those aged 3, 4 and 5 years and older had possibly participated in one, two and three MDA rounds respectively. The transmission of hookworm may have decreased as a result of the annual MDA campaigns.

MDA with DEC and albendazole achieved a reduction in hookworm prevalence in Indonesia from $25.3 \%$ to $5.9 \%$ [3]. Although on Nukufetau the hookworm prevalence in adults was high, without a pre-MDA baseline amongst adults comments on trends cannot be made. The initial hookworm prevalence was $50 \%$ in Indonesian residents older than 50 years and demonstrated a dramatic reduction in this age group after two rounds of MDA [3]. A single dose of $400 \mathrm{mg}$ albendazole achieved an average cure rate of $78 \%$ in 68 studies [9]. Hence, for Nukufetau after albendazole had been administered annually for three years, a lower prevalence would have been expected.

The coverage of MDA in Nukufetau, at least in the first and third round, was very good. However, compliance with the MDA may have affected the success of treatment, especially in the middle and older age groups, which showed higher prevalences of hookworm infection. Unfortunately, individual data on compliance was not available. However, at the mass treatment rounds, men were more likely to be unavailable for observed treatment owing to their being absent while fishing or travelling.

Rate of re-infection after treatment can be considerable [10], but the low prevalence of hookworm in children suggests that incidence is low and that re-infection is unlikely to account for the high adult prevalence. Trichuris eggs can survive for extended times in the environment as compared to hookworm eggs and larvae, which may have contributed to a higher prevalence of trichuriasis than hookworm infection after mass treatment. Additionally, hookworm may have developed resistance to albendazole. However, resistance of human hookworms to anthelmintics has not been definitely reported. Resistance to pyrantel was suspected in Australia in Ancylostoma duodenale with the strain susceptible to albendazole [11]. Reduced efficacy of mebendazole was reported in Mali [12] and after 5 years of intensive therapy in Zanzibar [13]. Although anthelmintic resistance is less likely to account for persistence of hookworm than non-compliance in MDA, standardised resistance testing should be conducted on this population of hookworms in Nukufetau $[14,15]$.

This study highlights the persistence of Trichuris infection after three rounds of MDA using albendazole and DEC. Studies from Haiti, India and Sri Lanka reported in contrast to our data reduction of the prevalence of trichuriasis after mass treatment with albendazole and DEC [16-18]. DEC has no significant activity against hookworm and Ascaris lumbricoides [19] and is unlikely to be active against T. trichiura. Albendazole has limited activity against Trichuris with prevalences after the standard single dose of $400 \mathrm{mg}$ declining between $23 \%$ to $48 \%[9,20,21]$ or showing no effect at all [10]. The prevalence of Trichuris was reduced between $7 \%$ and $48 \%$, the latter from a cohort study, of Trichuris in Indonesia after two rounds of MDA using albendazole and DEC [3]. A cure rate of 30\% with the same anthelminthic combination against $T$. trichiura was reported in Sri Lanka [22]. Ongoing transmission despite repeated MDA campaigns in Nukufetau is suggested by the high rate $(66 \%)$ of Trichuris in children under 5 years of age. Another anthelminthic, such as mebendazole or ivermectin, which has greater efficacy against Trichuris than albendazole should be used in Tuvalu to eliminate Trichuris. Mebendazole has been reported to have a high efficacy against Trichuris infections [23]. The data on efficacy of single dose ivermectin for $T$. trichiura are inconsistent with cure rates ranging from $0 \%$ to $88 \%$ [24-28], and two doses of ivermectin showed cure rates between $84 \%$ and $100 \%[29,30]$. Ivermectin with albendazole had a higher cure rate than albendazole alone (79\% versus 30\% respectively) [22].

The PICT share particular epidemiologic and ecological features that may have contributed to these different results. For example, the parasite fauna is different from other parts of the world, which is exemplified by the complete absence of ascariasis and the high prevalence of trichuriasis in our study population. Different strains with different susceptibilities to anthelmintic drugs may also prevail.

For Nukufetau chemotherapy should be combined with an integrated control strategy to reduce the contamination of the island with eggs [5]. Behaviours that lead to eggs gaining access to soil and surviving the two weeks required for development in the egg have not been investigated in PICT. Homes on Nukufetau have septic sewage 
systems, but the quality of systems is not high. Rain is the only available source of potable water and when rainwater tanks become depleted during the dry season, residents may be reluctant to use water for toilets and personal hygiene (TN, personal observation). An association between inadequate water supplies in schools and STH was found in 14 PICT [1]. Defecation on the beach or in the sea is not uncommon in Nukufetau (TN, personal observation). The survival of hookworm eggs and larvae and $T$. trichiura eggs in sea-water appear not to have been tested. Experimentally sodium chloride at $2 \%$ concentration and higher had a deleterious effect on development of hookworm eggs and larvae [31]; seawater contains approximately $3.5 \%$ sodium chloride. However, the embryo of Trichuris, protected by a thick shell, could potentially survive immersion in sea-water. This hypothesis warrants investigation as it has implications for management strategies for Trichuris in small island nations.

\section{Conclusion}

We have shown that on a remote island in the Western Pacific the spectrum of STH present in the general population is quite narrow with only hookworm and Trichuris infections present and that the prevalence of STH remains high after three rounds of MDA with albendazole and DEC. It appears that the MDA for lymphatic filariasis elimination has resulted in a significant reduction in hookworm prevalence in residents under 30 years of age. However, we assume based on previous data in children aged 5-12 years [1] and the high prevalence overall that annual community DEC and albendazole administration has had a minimal effect on $T$. trichiura prevalence. Alternative anthelmintics plus measures to reduce environmental contamination with helminth eggs need to be considered as part of an integrated STH control program.

\section{Competing interests}

The WHO Collaborating Centre for Lymphatic Filariasis received funding for filariasis research on Tuvalu from Glaxo Smith Kline, the manufacturers of albendazole.

\section{Authors' contributions}

RS: Assisted in project design, conducted the survey, performed laboratory examination, did statistical analysis and wrote the initial draft of the manuscript. FFL: Assisted in project design, conducted the survey, performed laboratory examination and contributed to the manuscript; $\mathrm{TN}$ : Assisted in project design and contributed to the manuscript; SH: Contributed to the manuscript; WM: Assisted in project design and contributed to the manuscript; DD: Assisted in project design and contributed to the manuscript; JH: Contributed to the manuscript.

\section{Acknowledgements}

The study was supported by a grant from Glaxo Smith Kline to the WHO Collaborating Centre for Lymphatic Filariasis at James Cook University.
Jorg Heukelbach was supported by an Endeavour Australia Research Scholarship. We wish to thank Vicki Saunders for statistical advice.

\section{References}

I. Hughes RG, Sharp DS, Hughes MC, Akau'ola S, Heinsbroek P, Velayudhan R, Schulz D, Palmer K, Cavalli-Sforza T, Galea G: Environmental influences on helminthiasis and nutritional status among Pacific schoolchildren. Int J Envir Hith Res 2004, 14:163-177.

2. Savioli L, Stansfield S, Bundy DA, Mitchell A, Bhatia R, Engels D, Montresor A, Neira M, Shein AM: Schistosomiasis and soil-transmitted helminth infections: forging control efforts. Trans Roy Soc Trop Med Hyg 2002, 96:577-579.

3. Oqueka T, Supali T, Ismid IS, Purnomo, Ruckert P, Bradley M, Fischer $P$ : Impact of two rounds of mass drug administration using diethylcarbamazine combined with albendazole on the prevalence of Brugia timori and of intestinal helminths on Alor Island, Indonesia. Filaria J 2005, 4:5.

4. Stephenson LS, Holland CV, Cooper ES: The public health significance of Trichuris trichiura. Parasitology 2000, I 2 I:S73-S95.

5. Urbani C, Palmer K: Drug-based helminth control in Western Pacific countries: a general perspective. Trop Med Int Health 200I, 6:935-944.

6. PacELF: PacELF Progress Report January - December 20042005 [http:// www.pacelf.org/reports/]. Suva, PacELF Home Office

7. Montresor A, Crompton DWT, Bundy DAP, Hall A, Savioli L: Guidelines for the evaluation of soil-transmitted helminthiasis and schistosomiasis at community level. 1998 [http://whqlib doc.who.int/hq/I998/WHO CTD SIP 98.I.pdf]. WHO/CTD/SIP/98

8. Mngomezulu N, Govere JM, Durrheim DN, Speare R, Viljoen L, Appleton C, Booman M: Burden of schistosomiasis and soiltransmitted helminth infections in primary school children in Mpumalanga, South Africa, and implications for control. S Afr J Sci 2002, 98:607-610.

9. Horton J: Albendazole: a review of anthelmintic efficacy and safety in humans. Parasitology 2000, I 2 I: I I3- I 32.

10. Saathoff E, Olsen A, Kvalsvig JD, Appleton CC: Patterns of geohelminth infection, impact of albendazole treatment and reinfection after treatment in schoolchildren from rural KwaZulu-Natal, South-Africa. BMC Infect Dis 2004, 4:27.

II. Reynoldson JA, Behnke JM, Pallant LJ, Macnish MG, Gilbert F, Giles S, Spargo RJ, Thompson RCA: Failure of pyrantel in treatment of human hookworm infections (Ancylostoma duodenale) in the Kimberley region of North West Australia. Acta Trop 1997, 68:301-312

12. de Clercq D, Sacko M, Behnke J, Gilbert F, Dorny P, Vercruysse J: Failure of mebendazole in treatment of human hookworm infections in the southern region of Mali. Am J Trop Med Hyg 1997, 57:25-30.

13. Albonico M, Bickle Q, Ramsan M, Montresor A, Savioli L, Taylor M: Efficacy of mebendazole and levamisole alone or in combination against intestinal nematode infections after repeated targeted mebendazole treatment in Zanzibar. Bull World Health Organ 2003, 81:343-352.

14. Albonico M, Engels D, Savioli L: Monitoring drug efficacy and early detection of drug resistance in human soil-transmitted nematodes: a pressing public health agenda for helminth control. Int J Parasitol 2004, 34: I 205-1210.

15. Albonico M, Wright V, Ramsan M, Haji HJ, Taylor M, Savioli L, Bickle $Q$ : Development of the egg hatch assay for detection of anthelminthic resistance in human hookworms. Int J Parasitol 2005, 35:803-8II.

16. Mani TR, Rajendran R, Sunish IP, Munirathinam A, Arunachalam N, Satyanarayana , Dash AP: Effectiveness of two annual, singledose mass drug administrations of diethylcarbamazine alone or in combination with albendazole on soil-transmitted helminthiasis in filariasis elimination programme. Trop Med Int Health 2004, 9:1030-1035.

17. de Rochars MB, Direny AN, Roberts JM, Addiss DG, Radday J, Beach MJ, Streit TG, Dardith D, Lafontant JG, Lammie PJ: Communitywide reduction in prevalence and intensity of intestinal helminths as a collateral benefit of lymphatic filariasis elimination programs. Am J Trop Med Hyg 2004, 7 I:466-470.

18. de Silva NR, Pathmeswaran A, Fernando SD, Weerasinghe CR, Selvaratnam RR, Padmasiri EA, Montresor A: Impact of mass chemo- 
therapy for the control of filariasis on geohelminth infections in Sri Lanka. Ann Trop Med Parasitol 2003, 97(4):421-425.

19. Meyrowitsch DW, Simonsen PE: Short communication: efficacy of DEC against Ascaris and hookworm infection in schoolchildren. Trop Med Int Health 200I, 6:739-742.

20. Bennett $A$, Guyatt $H$ : Reducing intestinal nematode infection: efficacy of albendazole and mebendazole. Parasitol Today 2000, 16:7I-74.

21. Adams VJ, Lombard CJ, Dhansay MA, Markus MB, Fincham JE: Efficacy of albendazole against the whipworm Trichuris trichiura - a randomised, controlled trial. S Afr Med J 2004, 94:972-976.

22. Ismail MM, Jayakody RL: Efficacy of albendazole and its combinations with ivermectin or diethylcarbamazine (DEC) in the treatment of Trichuris trichiura infections in Sri Lanka. Ann Trop Med Parasitol I 999, 93:50 I-504.

23. Legesse M, Erko B, Medhin G: Comparative efficacy of albendazole and three brands of mebendazole in the treatment of ascariasis and trichuriasis. East Afr Med J 2004, 8I: I 34- I 38.

24. Belizario VY, Amarillo ME, de Leon WU, de los Reyes AE, Bugayong MG, Macatangay BJ: A comparison of the efficacy of single doses of albendazole, ivermectin, and diethylcarbamazine alone or in combinations against Ascaris and Trichuris spp. Bull World Health Organ 2003, $81: 35-42$.

25. Freedman DO, Zierdt WS, Lujan A, Nutman TB: The efficacy of ivermectin in the chemotherapy of gastrointestinal helminthiasis in humans. J Infect Dis 1989, 159: II5I-II53.

26. Taticheff S, Kebede A, Bulto T, Werkeneh W, Tilahun D: Effect of ivermectin (Mectizan) on intestinal nematodes. Ethiop Med J 1994, 32:7-15.

27. Marti H, Haji HJ, Savioli L, Chwaya HM, Mgeni AF, Ameir JS, Hatz C: A comparative trial of a single-dose ivermectin versus three days of albendazole for treatment of Strongyloides stercoralis and other soil-transmitted helminth infections in children. Am J Trop Med Hyg 1996, 55:477-48I.

28. Ranque S, Chippaux JP, Garcia A, Boussinesq M: Follow-up of Ascaris lumbricoides and Trichuris trichiura infections in children living in a community treated with ivermectin at 3monthly intervals. Ann Trop Med Parasitol 200I, 95:389-393.

29. Naquira C, Jimenez G, Guerra JG, Bernal R, Nalin DR, Neu D, Aziz $M$ : Ivermectin for human strongyloidiasis and other intestinal helminths. Am J Trop Med Hyg 1989, 40:304-309.

30. Heukelbach J, Wilcke T, Winter B, Sales de Oliveira FA, Sabóia Moura $\mathrm{RC}$, Harms G, Liesenfeld O, Feldmeier H: Efficacy of ivermectin in a patient population concomitantly infected with intestinal helminths and ectoparasites. Arzneimittelforschung 2004, 54:4|6-42I.

31. Nicholl W: Observations on the influence of salt and other agents in modifying the larval development of the hookworms: Ankylostoma duodenale and Necator americanus. Parasitology 1917, IX:155-189.

\section{Pre-publication history}

The pre-publication history for this paper can be accessed here:

http://www.biomedcentral.com/1471-2334/6/110/pre pub

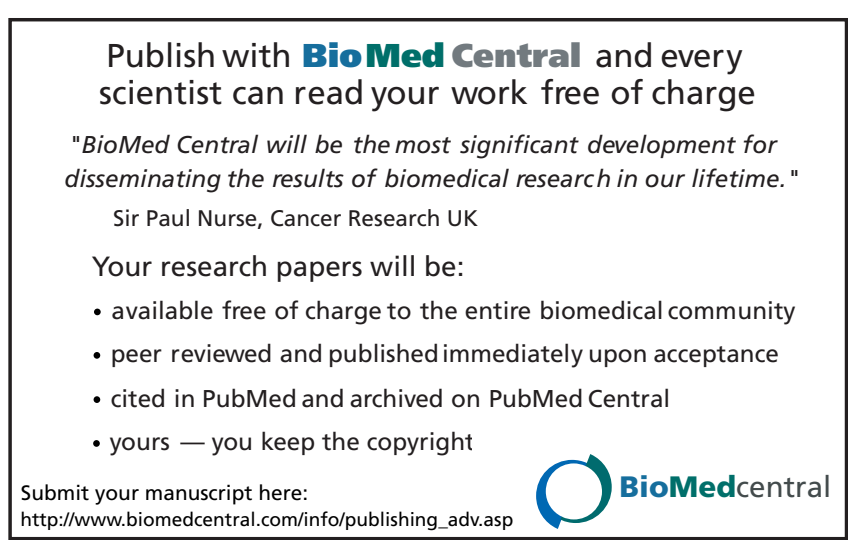

